\title{
UMA ANÁLISE SOCIOLINGUÍSTICA COMPARATIVA DE CONECTORES SEQUENCIADORES: FOCO NA ESCOLARIDADE
}

\section{A COMPARATIVE SOCIOLINGUISTIC ANALYSIS OF SEQUENCE CONNECTORS: FOCUS ON EDUCATION}

\author{
Maria Alice Tavares \\ Universidade Federal do Rio Grande do Norte, Brasil/CNPq ${ }^{1}$ \\ aliceflp@hotmail.com
}

\begin{abstract}
À luz da sociolinguística variacionista comparativa, tomo os conectores $e$, aí e então como variantes da variável discursiva denominada "sequenciação retroativo-propulsora de informações", responsável pelo estabelecimento de uma relação coesiva de continuidade e consonância entre enunciados. Tenho por objetivo principal comparar influências da escolaridade sobre esse fenômeno variável em Natal (RN), na região Nordeste do Brasil, e em Florianópolis (SC), na região Sul do Brasil. Os dados, obtidos em entrevistas sociolinguísticas, foram submetidos à análise estatística multivariada. Os resultados mostram que, em ambas as comunidades de fala, os conectores $e$ e então são favorecidos por indivíduos mais escolarizados, enquanto o conector aí, considerado típico de interações informais, é favorecido por indivíduos menos escolarizados. Esses resultados conformam-se à generalização sociolinguística que prevê correlação entre maiores níveis de escolaridade e formas positivamente avaliadas, e menores níveis de escolaridade e formas negativamente avaliadas, e evidenciam que tal generalização é aplicável a variáveis discursivas.
\end{abstract}

Palavras-chave: Sociolinguística comparativa. Conectores sequenciadores. Escolaridade. Generalização. Variável discursiva.

Keywords: Comparative sociolinguistics. Sequence connectors. Education. Generalization. Discursive variable.

Under the light of comparative variationist sociolinguistics, I take the connectors $e$, aí and então as variants of the discursive variable named "retroactive-propeller sequenciation of information", which is responsible for establishing a continuity and consonance cohesive link between utterances. I have as main objective to compare influences of education level on this variable phenomenon in Natal (RN), in Northeastern Brazil, and in Florianópolis (SC), in Southern Brazil. The data, obtained from sociolinguistic interviews, were submitted to multivariate statistical analysis. The results show that in both speech communities connectors $e$ and então are favored by more educated individuals, while connector aí, which is considered typical of informal interactions, is favored by less educated individuals. These results conform to the sociolinguistic generalization that predicts correlation between higher levels of education and positively evaluated forms, and lower levels of

\footnotetext{
1 Este trabalho está vinculado ao Projeto Variação e gramaticalização na indicação da SRPI: um estudo sociofuncionalista comparativo, que recebeu apoio do Conselho Nacional de Desenvolvimento Científico e Tecnológico/CNPq (processo no 308245/2011-3).
} 
education and negatively evaluated forms, bringing evidence that this generalization applies to discursive variables.

(Recibido: 26/01/2016; Aceptado: 19/06/2016)

\section{Introdução}

Apresento uma análise sociolinguística comparativa de um fenômeno de variação linguística que envolve uma variável discursiva, a sequenciação retroativo-propulsora de informações (cf. Tavares 2012, 2014), responsável pelo estabelecimento de uma relação coesiva de continuidade e consonância entre enunciados. As formas variantes de realização da sequenciação retroativopropulsora de informações mais frequentes no português brasileiro oral são os conectores sequenciadores $e$, aí e então (cf. Tavares 2012, 2014, Freitag et al. 2013, Santos 2003).

A seguir, temos ocorrências desses conectores provenientes de contextos muito similares: narrativas de experiência pessoal produzidas em entrevistas sociolinguísticas ${ }^{2}$ em trechos de introdução de discurso direto, com o verbo de elocução dizer no pretérito perfeito do indicativo. Essas ocorrências salientam a possibilidade de uso variável desses conectores.

1. Aí a minha mãe: "Ah! pois é, mas eu tenho que dar baixa nessa carteira." Aí o cara falou: "É, mas a senhora não quer nada?" E a minha mãe disse: "Quer nada o quê?" "É porque nós somos obrigados a vender um ônibus desses pra pagar ele." $\left(\right.$ FLP09) ${ }^{3}$

2. Quando ela abriu o olho, que olhou pro espelho, ela fez: "Eu tô parecendo uma bruxa". Quando ela disse isso, chegou gelei. Aí eu disse: "É o quê?" Ela disse: "Eu tô horrível!" (NAT25)

3. Mas ele insistiu e disse: "Olha, tem uma equipe de São Paulo, lá, do Professor Odair Pedroso, se for necessário nós podemos lhe mandar pra São Paulo fazer um curso." Então eu disse: "Se é assim, se desejam assim, eu posso tentar, se não decepcionar." Então eu fiquei, realmente três meses em treinamento com a equipe do Professor Odair Pedroso num- no Hospital Celso Ramos. (FLP21)

Considerando que variáveis discursivas, à semelhança de variáveis de qualquer nível gramatical, manifestam heterogeneidade ordenada e podem sofrer mudança (cf. Macaulay 2002, 2005, Buchstaller e D’Arcy 2009, Pichler 2010, 2013, Tagliamonte 2012), justifica-se o tratamento variacionista aplicado, neste estudo, à sequenciação retroativo-propulsora de informações.

Assim como ocorre nos demais níveis gramaticais, os padrões de variação de alternantes de nível discursivo podem ser condicionados por fatores diversos, linguísticos e extralinguísticos. Neste texto, abordo um fator de ordem extralinguística, o nível de escolaridade dos informantes, analisando a influência da escolarização continuada sobre o uso variável dos conectores sequenciadores $e$, aí e então. Testes de atitude linguística revelam que falantes brasileiros assinalam a existência de distinções estilísticas no emprego desses conectores: aí é apontado como típico de contextos de interação caracterizados por maior informalidade, ao passo que e então são, em geral, avaliados como estilisticamente neutros no que se refere ao grau de formalidade da situação (cf. Silva 2013, Tavares 2014).

\footnotetext{
${ }^{2}$ A entrevista sociolinguística é o instrumento utilizado com maior frequência como manancial de dados em pesquisas realizadas no âmbito da sociolinguística variacionista (cf. Milroy e Gordon 2003, Schilling-Estes 2007). Isso se deve a três razões em especial: a entrevista sociolinguística (i) permite a obtenção de dados de diversos fenômenos variáveis em quantidade suficiente para a realização de análises estatísticas; (ii) possibilita que sejam alcançados resultados quantitativos sólidos, replicáveis e comparáveis entre si; e (iii) facilita a descoberta de tendências de variação social, linguística e estilística de uma comunidade de fala (cf. Labov 1972, 1984, Macaulay 1991, Tagliamonte 2006). Para cumprir esses objetivos, a entrevista sociolinguística é conduzida por um entrevistador que incentiva o informante a falar sobre diversos temas e a deter a palavra a maior parte do tempo.

${ }^{3} \mathrm{O}$ código que segue ao dado identifica a sua fonte. Por exemplo, FLP09 = entrevista de Florianópolis de número 9. NAT corresponde à entrevista de Natal.
} 
É possível, pois, que o conector aí esteja sujeito a sanções no âmbito escolar que não atinjam os conectores e e então, o que poderia contribuir para uma diminuição da taxa de ocorrência daquele conector na fala de pessoas de níveis mais altos de escolaridade.

A questão da influência da escolaridade na distribuição quantitativa dos conectores sequenciadores $e$, aí e então é tratada aqui em uma perspectiva comparativa, através do cotejamento de resultados obtidos para duas comunidades de fala situadas em regiões distintas do Brasil: Florianópolis (SC), no Sul, e Natal (RN), no Nordeste. Do ponto de vista da sociolinguística variacionista, é de fundamental importância a realização de análises comparativas de fenômenos variáveis dentro de uma mesma língua ou mesmo interlinguisticamente, pois é com base nesse tipo de análise que podem ser testadas generalizações referentes à variação e à mudança linguística já consagradas na literatura da área e tidas como válidas para todas ou grande parte das comunidades linguísticas (cf. seção 2).

Essas generalizações foram propostas com base na investigação contrastiva de fenômenos variáveis de nível não discursivo (cf. Tagliamonte e D’Arcy 2009, Tagliamonte 2012, Pichler 2013). Aplicá-las ao caso da sequenciação retroativo-propulsora de informações permite verificar a possibilidade de sua extensão para fenômenos de nível discursivo no que se refere ao português brasileiro.

Nessa ótica, tenho por objetivos, neste texto, (i) analisar o condicionamento do nível de escolaridade dos informantes sobre o uso dos conectores sequenciadores $e$, aí e então nas comunidades de fala de Natal e de Florianópolis; (ii) comparar os resultados referentes à distribuição desses conectores quanto ao nível de escolaridade em Natal e em Florianópolis, levantando semelhanças e diferenças; (iii) verificar se generalizações sociolinguísticas já consagradas a respeito da relação entre o uso de formas variantes e o nível de escolaridade dos indivíduos aplicam-se ao caso dos conectores sob enfoque.

$\mathrm{Na}$ próxima seção, descrevo a variável discursiva que denomino sequenciação retroativopropulsora de informações. A seguir, sintetizo pressupostos teórico-metodológicos da sociolinguística variacionista centrais para este estudo, dando especial relevo a sua vertente sociolinguística comparativa. Na sequência, descrevo os procedimentos metodológicos adotados, teço as hipóteses relativas à distribuição dos conectores $e$, aí e então no que tange ao nível de escolaridade dos informantes, e analiso os resultados obtidos à luz de generalizações sociolinguísticas ligadas à escolarização.

\section{A sequenciação retroativo-propulsora de informações}

A sequenciação retroativo-propulsora de informações é o domínio funcional responsável por marcar a introdução de enunciados no discurso em relação coesiva de continuidade e consonância, de modo que o primeiro enunciado serve de base para a interpretação do segundo. A sequenciação retroativo-propulsora de informações possui dupla natureza: anafórica (retroação) e catafórica (propulsão), visto que se caracteriza pela indicação de uma “(...) ancoragem em instância preliminar do discurso, viabilizando a continuidade deste sempre em perfeita consonância com uma sequência informacional já posta" (Risso 1996: 431).

$E$, aí e então são os conectores mais frequentemente utilizados, nos corpora selecionados para esta pesquisa, como indícios linguísticos para que o ouvinte perceba a relação de sequenciação entre enunciados. 
O emprego desses conectores gera a expectativa de que algo novo será posto no discurso, em continuidade e consonância com o já dado. Esses conectores apresentam, portanto, significado procedural, não conceptual, isto é, eles não alteram o conteúdo proposicional dos segmentos que interligam; seu papel é "revelar ou tornar explícitas as conexões que já operam em um texto" (Lenker 2011:2). ${ }^{4}$

As formas gramaticais que desempenham papéis de natureza discursiva são, de acordo com Pichler (2010: 596), "recurso indispensável para os interlocutores na construção e na interpretação do discurso, bem como no estabelecimento e na manutenção da interação social" ". Os conectores sequenciadores $e$, aí e então atuam no plano da "construção" e "interpretação do discurso": indicam que o enunciado prévio se relaciona com o enunciado subsequente e instigam o ouvinte a procurar por possíveis relações semântico-pragmáticas existentes entre os enunciados assim interligados. Essas relações podem ser percebidas a partir da soma de diversos indícios: o que foi dito antes, o que se seguiu, além de inferências e implicaturas em jogo no momento da interação.

As relações semântico-pragmáticas mais frequentemente encontradas nos contextos de uso dos conectores sequenciadores $e$, aí e então são: (i) sequenciação textual: sinalização da ordem pela qual as unidades conectadas sucedem-se ao longo do tempo discursivo, salientando o encadeamento de uma porção textual anterior com uma posterior (como em (4) e (5) adiante); (ii) sequenciação temporal: introdução de eventos na ordem de ocorrência no tempo (valor de a seguir, depois), isto é, indicação de que o evento B acontece depois do evento A (como em (6) e (7)); (iii) consequência: introdução de informações que representam consequência em relação a uma causa mencionada previamente (como em (8) e (9)). O movimento anafórico/catafórico característico da sequenciação retroativo-propulsora de informações se faz presente a cada caso.

4. Então quando eu f- disse isso na minha mente, minha língua começou a suavizar e eu comecei a abrir. Quando eu abri, não vi mais ninguém. Então eu acho que são experiências espirituais que a gente tem na vida, né? e que Deus dá quando a gente tá merecendo. Naquele dia eu tenho certeza que eu tava merecendo ver meu irmão. (NAT25).

5. Agora está tudo bom, tudo fácil, né? [O]- [o tempo]- O tempo que eu me criei não era fácil, não, era fogo. $E$ a gente, às vezes, ainda tinha que buscar lenha até no mato. Às vezes não tinha lenha. O homem que a gente comprava lenha não trazia. (FLP08).

6. Aí faço o peito de frango, cozinho o peito de frango, desfio o peito de frango, deixo ele de lado. Aí vou pro macarrão, deixo o macarrão cinco minutinhos no fogo cozinhando, tiro, aí começo a montar a lasanha. (NAT26).

7. Ele pegava o bambu, pegava- amarrava uma tocha $e$ tocava fogo. (FLP01).

8. Acho que se tivesse emprego não- não tinha tanto assim- Até mesmo que nem eles fazem agora, exige estudo, né? Então o pessoal estuda pra manter o emprego, né? Aí eu acho que mudaria, né? muita coisa. (NAT34).

9. A gente dava o banho, dava um purgante, aí a criança ficava boa. (FLP08). ${ }^{6}$

Cumpre esclarecer a aplicação da noção de domínio funcional à sequenciação retroativopropulsora de informações. Emprego “domínio funcional” no sentido de Givón (1984) em referência a áreas funcionais gerais (ou macrodomínios) como TAM (tempo/ aspecto/ modalidade), caso, referência, voz, possessão, ou áreas mais estritas (microdomínios), como o tempo futuro, o aspecto inceptivo, a modalidade epistêmica, o caso instrumental, a dêixis, a detransitivização, a predicação possessiva etc. (cf. Givón 1984, 1995, 2002).

\footnotetext{
${ }^{4}$ Para um maior detalhamento dos critérios que embasam a decisão teórico-metodológica de tomar a sequenciação retroativo-propulsora de informações como variável linguística, conferir Tavares $(2012,2014)$.

${ }^{5}$ As traduções são de minha responsabilidade.

${ }^{6}$ Os conectores $e$, aí e então são empregados variavelmente na indicação de todas as relações semântico-pragmáticas listadas acima, mas, por uma questão de espaço, apresento apenas dois exemplos de cada relação.
} 
Nessa ótica, o domínio funcional é entendido como um fenômeno superordenado, recobrindo áreas funcionais mais amplas (macrodomínios) ou mais estritas (microdomínios). Assim sendo, o que é tratado como domínio numa certa perspectiva pode ser tratado como macrodomínio ou microdomínio em outras perspectivas. A noção de domínio funcional emprega-se, portanto, em referência a diferentes domínios superordenados nas hierarquias funcionais em que se distribuem as funções da língua: um dado tempo é um microdomínio em relação ao domínio TAM, por exemplo, mas podemos tratar qualquer um dos tempos como "domínio funcional".

Por sua vez, a sequenciação retroativo-propulsora é um domínio funcional que pode ser definido como microdomínio relativamente ao macrodomínio geral da articulação de enunciados, que, por sua vez, engloba dois microdomínios amplos: parataxe/coordenação e hipotaxe/subordinação. A sequenciação retroativo-propulsora de informações integra, como microdomínio, o domínio da parataxe/coordenação. Sintetizando, temos as seguintes relações de superordenação: articulação de enunciados > parataxe/coordenação > sequenciação retroativopropulsora de informações. É o (micro)domínio da sequenciação retroativo-propulsora de informações que tomo como variável linguística alvo desta pesquisa. ${ }^{7}$

\section{Sociolinguística comparativa: foco nas generalizações de natureza extralinguística}

A sociolinguística variacionista observa a língua do ponto de vista de sua heterogeneidade, mostrando que a variabilidade linguística é generalizada, ocorrendo com frequência em qualquer um dos níveis da língua (fonológico, morfossintático, pragmático/discursivo) (cf. Labov 1972, Tagliamonte 2012). Isso significa que os falantes seguidamente fazem uma seleção - consciente ou inconscientemente - entre dois ou mais sons, palavras ou construções disponíveis, em uma mesma comunidade de fala e em um mesmo período de tempo, para a expressão de um certo significado e/ou de uma certa função gramatical. As formas linguísticas que possuem um mesmo significado e/ou função são denominadas "formas variantes", caracterizadas por manifestarem equivalência referencial e/ou funcional (cf. Watt 2007). Esse é o caso dos conectores sequenciadores $e$, aí e então, que possuem a mesma função gramatical, a indicação de sequenciação retroativo-propulsora de informações, e que são, aqui, tomados como formas variantes. Um conjunto de formas variantes recebe o rótulo de "variável linguística" e constitui o objeto de estudo da sociolinguística variacionista.

A sociolinguística variacionista trouxe à tona o fato de que a variação linguística é um fenômeno regular, e, portanto, pode ser sistematizada e investigada quantitativamente. É a quantificação dos dados relativamente a traços de seu contexto de uso que possibilita ao sociolinguista a observação de padrões regulares de distribuição das variantes face a possíveis influências de natureza social, linguística e estilística (cf. Labov 1972). São passos centrais para a análise: (i) levantamento de hipóteses que possam explicar as tendências sistemáticas de um dado fenômeno variável e operacionalização dessas hipóteses através da elaboração de grupos de fatores condicionadores, que representam contextos linguísticos, estilísticos e sociais capazes de favorecer ou desfavorecer a seleção de uma ou outra das formas que disputam determinado emprego; (ii) coleta dos dados relevantes, que são codificados em consonância com os grupos de fatores condicionadores e submetidos a tratamento estatístico probabilístico, pelo qual frequências e pesos relativos são associados aos diversos fatores, a fim de que se possa medir a restrição que cada um deles exerce sobre a presença de uma ou outra das variantes; (iii) interpretação dos resultados quantitativos, procurando-se chegar a uma explicação para o fato de os falantes efetuarem uma certa

\footnotetext{
${ }^{7}$ Outros estudos feitos sob a égide da sociolinguística variacionista também têm relacionado a noção de variável linguística à noção de domínio funcional (cf. Pichler 2010, 2013, Tagliamonte e D’Arcy 2007, Tagliamonte, Durham e Smith 2014, Torres Cacoullos 2001, Torres Cacoullos e Walker 2009, entre outros).
} 
escolha linguística em detrimento de outra(s). É esse mapeamento sistemático de condicionamentos sociais, linguísticos e estilísticos sobre a variação que permite o estabelecimento de generalizações e até mesmo princípios universais de variação e mudança. No caso deste texto, detenho-me na questão dos condicionamentos do nível de escolaridade sobre o uso de $e$, aí e então como conectores.

Entre as sugestões para futuras investigações que aparecem, em geral, na seção destinada às considerações finais em trabalhos feitos sob a perspectiva da sociolinguística variacionista, é comum que seja apontada a possibilidade de realização de análises comparativas dos resultados obtidos para o fenômeno estudado com resultados obtidos por pesquisas efetuadas em outras regiões do Brasil, que tomem o mesmo ou semelhante objeto de estudo. No entanto, as análises sociolinguísticas comparativas de grande extensão ainda são raras no Brasil, talvez por conta das dificuldades que sua execução implica, como veremos a seguir.

Tagliamonte (2002: 729) afirma que a "comparação sempre esteve na raiz da sociolinguística", permitindo a construção de generalizações através do cotejamento de amostras de dados em tempo real e em tempo aparente. A principal vantagem dessas análises é que elas possibilitam a aplicação e o refinamento de generalizações sociolinguísticas já consagradas na literatura da área, além do que podem ensejar a proposição de novas generalizações. Segundo Tagliamonte (2015):

O estudo quantitativo da variação e da mudança linguística é um empreendimento em evolução há quase 50 anos (...). A investigação nessa área acumulou extensas evidências provenientes de uma vasta gama de comunidades e incontáveis traços linguísticos. As evidências que vêm sendo acumuladas fundamentam princípios gerais de mudança linguística (Labov 1994, 2001, 2010) e estudos em curso atestam a sua ampla aplicabilidade (por exemplo, Labov 2007, Tagliamonte e D'Arcy 2009). (Tagliamonte 2015: 1)

Temos disponível, abrangendo diferentes dialetos de línguas distintas, estudos variacionistas que parecem apontar para as mesmas ou similares direções de variação e de mudança, dos quais foram extraídas generalizações ou princípios de dimensão social do tipo (cf. Labov 2001, [1969] 2003, 2010, Tagliamonte 2012):

(i) em situações de variação estável, as mulheres, em média, apresentam um menor desvio em relação à norma de prestígio de sua comunidade de fala em contraste com os homens;

(ii) as mulheres costumam alternar mais o estilo de fala em comparação com os homens;

(iii) as mudanças linguísticas que ocorrem abaixo do nível de percepção consciente (change from below) geralmente têm sua origem em um grupo socioeconômico intermediário;

(iv) nesse tipo de mudança, as mulheres fazem maior uso das variantes inovadoras;

(v) nas mudanças linguísticas que ocorrem acima do nível de percepção consciente (change from above), as mulheres tendem a adotar variantes que estão em processo de difusão, vindas de outras comunidades de fala, ao passo que os homens tendem a dar preferência a variantes locais;

(vi) é comum haver um pico de uso das formas inovadoras na fala dos adolescentes e jovens adultos, especialmente daqueles com idades entre 17 e 20 anos;

(vii) níveis mais altos de escolaridade se correlacionam com traços linguísticos avaliados positivamente pela comunidade de fala - os traços linguísticos ditos "prestigiados"; em contraparte, níveis mais baixos de escolaridade se correlacionam com traços linguísticos avaliados negativamente pela comunidade de fala - os traços linguísticos tidos como informais ou mesmo estigmatizados. 
Dessas generalizações, a última envolve o nível de escolaridade, alvo deste estudo, cabendo, pois, aprofundar a questão. A escola pode exercer influência sobre as escolhas linguísticas de quem passa por seus bancos, visto que é especialmente através da escolarização continuada que vamos sendo alertados sobre a existência de formas de maior e de menor prestígio, e que somos estimulados a evitar o uso dessas últimas, notadamente em situações de maior formalidade (cf. Ramos e Duarte 2003, Votre 2003, Coelho et al. 2015). Labov (2001), ao comentar resultados de uma pesquisa que investigou diversas variáveis linguísticas na Filadélfia (EUA), concluiu que, nessa comunidade de fala e possivelmente em todas as demais, o efeito da educação é cumulativo, dependendo muito mais de quanto tempo de escolarização têm as pessoas do que do background educacional da família de origem. Ou seja, quanto maior o nível de escolaridade de um indivíduo, mais ele tenderá a fazer uso das formas linguísticas detentoras de prestígio social.

O rastreamento dos condicionamentos à variação e à mudança em apenas uma comunidade de fala é obviamente insuficiente para a testagem ou proposição de generalizações. Por exemplo, como podemos saber se os conectores sequenciadores manifestam um mesmo comportamento no que tange à sua distribuição por nível de escolaridade no português brasileiro como um todo? Como podemos verificar se as generalizações apresentadas acima no que concerne à correlação entre o nível de escolaridade e o uso de formas variantes mais e menos prestigiadas são válidas em todas as regiões brasileiras no que diz respeito ao caso específico dos conectores sequenciadores?

É preciso, pois, empreender estudos sociolinguísticos comparativos, levando-se em conta diferentes comunidades de fala. No entanto, há alguns obstáculos a serem enfrentados por quem decide realizar um estudo desse tipo. Geralmente, cada pesquisador utiliza um corpus e uma metodologia próprios, que podem diferir bastante do corpus e da metodologia utilizados por outros pesquisadores.

Além disso, embora se trate de estudos variacionistas, é possível que sejam adotadas interfaces teóricas um pouco ou bastante distintas (linhas mais formais ou mais funcionais, por exemplo). Daí surge o problema: qualquer diferença teórico-metodológica prejudica as comparações, podendo até mesmo inviabilizar a proposição de generalizações refinadas e confiáveis.

Por essa razão, os resultados relativos ao controle das influências do nível de escolaridade sobre o uso dos conectores sequenciadores apresentados a seguir são oriundos de uma pesquisa em que recorri a uma série de estratégias visando maior aproximação entre os dois conjuntos de dados analisados. Nessa pesquisa, em que foram cotejados dados provindos de duas comunidades de fala, Natal e Florianópolis, os aspectos em comum foram: (i) o mesmo recorte do objeto de estudo - a sequenciação retroativo-propulsora de informações; (ii) os mesmos pressupostos teóricometodológicos; (iii) a mesma fonte de dados, a entrevista sociolinguística; (iv) o mesmo número de informantes; (v) a mesma estratificação social dos informantes (quanto à idade, ao gênero e ao nível de escolaridade); (vi) os mesmos grupos de fatores linguísticos e extralinguísticos testados; (vii) o mesmo instrumental estatístico.

Na próxima seção, descrevo os procedimentos metodológicos seguidos para a realização da investigação, delineio as hipóteses concernentes à influência do nível de escolaridade do informante sobre o uso dos conectores sequenciadores $e$, aí e então em Natal e em Florianópolis, e analiso os resultados obtidos.

\section{Variação entre conectores sequenciadores: foco no nível de escolaridade}


Analisei 1.047 dados produzidos em 16 entrevistas sociolinguísticas feitas com informantes de Natal e 1.241 dados produzidos em 16 entrevistas sociolinguísticas feitas com informantes de Florianópolis.

Esses informantes foram homogeneamente estratificados em relação ao gênero (feminino e masculino), à idade (25 a 49 anos e mais de 50 anos), e à escolaridade (Ensino Fundamental 1 completo, o que equivale a cerca de quatro a cinco anos de escolarização e Ensino Médio completo (o que equivale a cerca de onze a doze anos de escolarização)), como sintetizado no quadro a seguir.

\begin{tabular}{|c|c|c|c|c|}
\cline { 2 - 5 } \multicolumn{1}{c|}{} & \multicolumn{2}{c|}{ FEMININO } & \multicolumn{2}{c|}{ MASCULINO } \\
\hline ESCOLARIDADE & 25 a 45 anos & + de 50 anos & 25 a 45 anos & + de 50 anos \\
\hline Fundamental 1 & 2 & 2 & 2 & 2 \\
\hline Ensino Médio & 2 & 2 & 2 & 2 \\
\hline
\end{tabular}

Quadro 1: Distribuição dos informantes de cada comunidade de fala de acordo com as células sociais Fonte: Elaboração própria

As entrevistas de Natal foram realizadas entre os anos de 2013 e 2015, e integram o banco de dados FALA-Natal (BDFN). As entrevistas de Florianópolis foram realizadas na primeira metade da década de 1990 e integram o banco de dados Variação Linguística na Região Sul do Brasil (VARSUL). Uma vez que os conectores sequenciadores são bastante recorrentes na oralidade, considero apenas os trinta minutos finais das entrevistas tanto de Natal quanto de Florianópolis, que têm cada uma cerca de sessenta minutos de duração.

Controlei como grupos de fatores condicionadores, além do nível de escolaridade, a relação semântico-pragmática, o nível de articulação, o grau de conexão, o gênero e a idade do informante ${ }^{8}$. Submeti os dados a tratamento quantitativo através do programa estatístico GOLDVARB X (cf. Sankoff et al. 2005), para cálculo de frequências, percentuais e pesos relativos ${ }^{9}$, e para a identificação da ordem de significância dos grupos de fatores. Realizei rodadas binárias do programa para cada uma das comunidades de fala, considerando cada variante versus as demais.

Neste texto, apresento os resultados referentes ao nível de escolaridade, grupo de fatores que foi selecionado como condicionador do emprego dos conectores sequenciadores nas duas amostras de dados consideradas. Em relação à comunidade de fala de Natal, esse grupo de fatores foi selecionado, pelo GOLDVARB X, na seguinte ordem de significância: em segundo lugar para então, em terceiro lugar para aí e em quinto lugar para $e$. Já em Florianópolis, a ordem de significância do nível de escolaridade foi a seguinte: em quarto lugar para aí e para então, e em quinto lugar para $e$.

\footnotetext{
${ }^{8}$ Controlei três relações semântico-pragmáticas indicadas pelos conectores: sequenciação textual, sequenciação temporal e consequência; e quatro níveis de articulação: entre orações, entre segmentos tópicos, entre subtópicos e entre tópicos. O grau de conexão foi avaliado através de um valor numérico atribuído conforme havia alteração de elementos entre a oração introduzida pelo conector e a oração precedente (por exemplo, alteração quanto a sujeito, tempo, aspecto, modo, presença de elementos interferentes etc.), do que resultou uma escala que foi do maior grau de conexão (equivalente ao valor 0 ) ao menor grau de conexão (equivalente ao valor 5).

${ }^{9} \mathrm{O}$ peso relativo é uma medida multidimensional ou multivariada importante para a pesquisa variacionista, pois resulta do controle simultâneo de vários elementos contextuais (no formato de múltiplas variáveis independentes/grupos de fatores) capazes de influenciar a variável linguística. Em uma análise multivariada, "(...) cada efeito de um fator na análise é calculado enquanto são controlados, até o máximo possível, os outros fatores” (Guy e Zilles 2007: 100). Os pesos relativos variam de 0 a 1 . Quanto mais próximo de 0 for o peso, menos influente é o fator que o recebeu; quanto mais próximo de 1 , maior é a influência. Um peso de valor 0.50 tende a ser indiferente.
} 
Passo agora a tecer as hipóteses. Existem situações de variação em que as variantes são avaliadas, pelos membros da comunidade de fala, quanto a seu grau de prestígio social. Nessas situações, tende a haver uma correlação entre o nível de escolaridade dos indivíduos e sua taxa de uso de certas variantes, no sentido de que, quanto mais anos passados na escola, maior deverá ser o uso das formas que têm conceito social positivo, especialmente em contextos de interação caracterizados por maior formalidade, sejam de fala ou de escrita.

O conector aí costuma ser considerado, pelos professores de língua portuguesa, como típico de situações de interação informais e, às vezes, como vício de linguagem a ser combatido (cf. Abreu 1992, Santos 2003, Tavares 2014). Em um teste de atitude linguística que realizei com informantes nativos de Florianópolis (SC), observei que esse tipo de avaliação negativa parece ser partilhada pelos florianopolitanos em geral. Nesse teste de atitude, o conector aí foi apontado como inadequado para situações de interação mais formais, em contraste com os conectores $e$ e então, tidos como possíveis nessas situações ${ }^{10}$. Na opinião dos florianopolitanos, embora $e$ e então possam aparecer na fala informal, também podem ser utilizados em situações em que maior formalidade é necessária (por exemplo, em palestras e em textos produzidos para concursos públicos), ao passo que aí deve ser evitado nesse tipo de situação (cf. TAVARES, 2014). O conector aí é, portanto, uma forma estilisticamente marcada em Florianópolis, sendo relacionado, pelos falantes, a contextos informais.

Em Natal, Silva (2013) conduziu, junto a dois grupos de alunos do Ensino Fundamental 2 (que vai do $6^{\circ}$ ao $9^{\circ}$ ano de escolarização) e seus professores de língua portuguesa, um teste de atitude linguística versando a possibilidade de uso dos conectores $e$, aí e então em situações de interação mais e menos formais.

Esse teste trouxe à tona que: (i) aí é avaliado, pelos alunos, como um conector impróprio para contextos formais de uso da língua, embora possa ser usado livremente em contextos informais, tanto de fala quanto de escrita - parece tratar-se, portanto, de um conector caracterizado estilisticamente como ligado ao registro informal; (ii) $e$ e então foram referidos pelos alunos como tendo uso possível em situações mais e menos formais - trata-se, pois, de formas não marcadas estilisticamente, isto é, formas que podem aparecer em contextos mais ou menos formais sem chamar atenção especial (poderíamos dizer, talvez, que são formas estilisticamente neutras, ao menos na comunidade de fala em questão); (iii) um dos professores de língua portuguesa aponta que o emprego de aí como conector deve ser restringido em situações formais, de fala e de escrita; (iv) o outro professor defende que esse emprego seja evitado em qualquer situação que envolva a conexão de partes do texto, isto é, ele não recomenda o uso da forma aí como conector, mesmo em situações de registro informal ${ }^{11}$.

Segundo Labov (1972), as taxas de ocorrência de certas variantes de menor prestígio podem ser correlacionadas ao papel social assumido pelas pessoas, o que não significa que elas nunca utilizem tais variantes, mas sim que podem ser mais atentas às situações em que as utilizam, evitando-as quando maior formalidade se fizer necessária.

\footnotetext{
${ }^{10}$ Apliquei o teste de atitude linguística no ano de 2002 a um pequeno grupo de florianopolitanos, composto por dois pré-adolescentes cursando a quarta série (equivalente ao atual quinto ano) do Ensino Fundamental 1, dois adolescentes cursando a oitava série (equivalente ao atual nono ano) do Ensino Fundamental 2, quatro adolescentes cursando o $3^{\circ}$ ano do Ensino Médio e três adultos, um com Ensino Fundamental 2 completo e dois com Ensino Médio completo, todos naturais de Florianópolis. Informações mais detalhadas sobre esse teste de atitude linguística podem ser obtidas em Tavares (2014).

${ }^{11}$ Participaram do teste de atitude linguística conduzido por Silva (2013) um total de 64 alunos matriculados em duas escolas municipais de Natal no ano de 2012. Foram 32 alunos de cada escola, distribuídos homogeneamente quanto ao gênero (feminino e masculino) e o nível de escolaridade (cursando o sexto e o nono ano do Ensino Fundamental 2). Também participaram do teste de atitude os professores de língua portuguesa desses alunos, um professor por escola.
} 
Assim, podemos supor que os professores de língua portuguesa, devido a seu papel social comumente relacionado ao ensino da norma culta da língua, não apenas procurem reduzir o uso do conector aí quando adotam um registro mais formal, mas também busquem combater esse uso na escrita e mesmo na fala de seus alunos. Disso são testemunhas as seguintes declarações feitas por participantes dos testes de atitude linguística aplicados por Silva (2013) e Tavares (2014):

- "Aí, esse conector é usado mais na linguagem informal então não ficaria bom de ver em critério de um professor detalhista." (aluno do $9^{\circ}$ ano do Ensino Fundamental 2, Natal, 2012) (Silva 2013: 79)

- "Uma vez, quando eu estava na sexta série, falei 63 aí para contar a história do livro "Rainha das Neves" e o professor contou todos e depois me repreendeu." (A., 17 anos, aluna do $3^{\circ}$ ano do Ensino Médio, Florianópolis, 2002) (Tavares 2014: 384)

Esses depoimentos, feitos por quem passou pelos bancos escolares, desvelam o olhar atento dos professores ao uso do conector aí. Tal atenção pode contribuir para uma diminuição da taxa de uso desse conector por parte de indivíduos com maior tempo de escolarização, e, portanto, maior contato com professores de língua portuguesa e suas sanções - além de maior contato com livros didáticos, a exemplo de Travaglia, Rocha e Arruda-Fernandes (2009), destinado ao $9^{\circ}$ ano do ensino fundamental, que alerta os alunos, a respeito do emprego de aí como conector:

"Este uso do aí como encadeador de episódios na narrativa não é muito aceito na norma urbana de prestígio. Troque o aí por outro recurso de acordo com a norma urbana de prestígio"12 (Travaglia et al. 2009: 309).

Considerando os fatos expostos acima, tracei a hipótese de que o uso de aí, conector marcado estilisticamente como informal (e, por vezes, até estigmatizado) deveria ser menor na fala de indivíduos que tivessem um maior tempo de contato com a escolarização formal (no caso deste estudo, aqueles com Ensino Médio completo) e, em decorrência, maior experiência com traços mais formais da língua portuguesa, em sua modalidade oral e escrita, bem como possível maior sujeição à pressão escolar para o abandono de formas avaliadas como de menor prestígio, caso do conector em apreço. Em contraparte, $e$ e então seriam favorecidos na fala desses indivíduos, como alternativas de maior prestígio - ou, ao menos, estilisticamente neutras - para indicar a sequenciação de informações.

Nas tabelas a seguir constam os resultados obtidos pelo controle da influência do nível de escolaridade sobre o uso dos conectores sequenciadores $e$, aí e então em Natal e em Florianópolis, respectivamente.

\begin{tabular}{|c|c|c|c|c|c|c|c|c|c|}
\cline { 2 - 10 } \multicolumn{1}{c|}{} & \multicolumn{3}{c|}{ E } & \multicolumn{3}{c|}{ AÍ } & \multicolumn{3}{c|}{ ENTÃO } \\
\hline ESCOLARIZAÇÃO & Ap./Tot. & \% & PR & Ap./Tot. & \% & PR & Ap./Tot. & \% & PR \\
\hline EF1 completo & $242 / 581$ & 42 & 0.47 & $280 / 581$ & 48 & $\mathbf{0 . 6 2}$ & $59 / 581$ & 10 & 0.40 \\
\hline EM completo & $229 / 466$ & 49 & $\mathbf{0 . 5 4}$ & $129 / 466$ & 28 & 0.40 & $108 / 466$ & 23 & $\mathbf{0 . 6 1}$ \\
\hline TOTAL & $471 / 1.047$ & 45 & & $409 / 1.047$ & 39 & & $167 / 1.047$ & 16 & \\
\hline
\end{tabular}

Tabela 1: Influência do nível de escolaridade sobre o uso de $e$, aí e então - Natal

Fonte: Elaboração própria

\footnotetext{
${ }^{12}$ Os autores do livro didático consideram que a variedade urbana de prestígio é “(...) a variedade utilizada pelos grupos sociais de maior prestígio social (político, econômico e cultural)” (Travaglia et al. 2009: 3).
} 
Os conectores $e$ e então são condicionados favoravelmente na fala de informantes com Ensino Médio completo e desfavorecidos na fala de informantes com Ensino Fundamental 1 completo, confirmando a expectativa inicial de haver uma maior correlação do uso desses conectores com o grupo de indivíduos que teve mais tempo de contato com a escolarização formal.

É preciso notar, porém, que o efeito da escolarização parece ser mais leve sobre $e$, que apresenta maior proximidade entre frequências e pesos relativos, do que sobre então, que apresenta maior distanciamento no que se refere a sua distribuição quantitativa nos dois níveis de escolaridade controlados. Esses resultados indicam que a escolarização continuada pode estar exercendo mais efeito sobre o aumento da taxa de uso de então em comparação com $e$.

A escola parece influenciar também o emprego de aí: observa-se haver uma forte inclinação para que esse conector ocorra na fala dos informantes de menor nível de escolaridade, com apenas o Ensino Fundamental 1 concluído. Paralelamente, ocorre uma redução de sua taxa de ocorrência na fala dos informantes mais escolarizados, no que se opõe a $e$, e, especialmente, a então. Tais resultados também vão ao encontro da expectativa inicial.

\begin{tabular}{|c|c|c|c|c|c|c|c|c|c|}
\hline & \multicolumn{3}{|l|}{$\boldsymbol{E}$} & \multicolumn{3}{|c|}{$A \dot{I}$} & \multicolumn{3}{|c|}{ ENTÃO } \\
\hline ESCOLARIZAÇÃO & Ap./Tot. & $\%$ & PR & Ap./Tot. & $\%$ & PR & Ap./Tot. & $\%$ & PR \\
\hline EF1 completo & $260 / 640$ & 41 & 0.46 & $253 / 640$ & 39 & 0.59 & $127 / 640$ & 20 & 0.45 \\
\hline EM completo & $288 / 601$ & 48 & 0.54 & $135 / 601$ & 22 & 0.40 & $178 / 601$ & 30 & 0.55 \\
\hline TOTAL & $548 / 1.241$ & 44 & & $388 / 1.241$ & 31 & & $305 / 1.241$ & 25 & \\
\hline
\end{tabular}

Tabela 2: Influência do nível de escolaridade sobre o uso de $e$, aí e então - Florianópolis Fonte: Elaboração própria

De modo similar a Natal, em Florianópolis, e e então são favorecidos entre os informantes com Ensino Médio, e desfavorecidos entre os informantes com Ensino Fundamental 1. No entanto, verifica-se que o peso relativo atribuído a então relativamente aos informantes com Ensino Médio é maior em Natal (0.61) do que em Florianópolis (0.55). Quanto a aí, em Florianópolis, seu uso é desfavorecido na fala dos informantes com Ensino Médio; em contraste, é favorecido na fala dos informantes com Ensino Fundamental 1.

Enfim, em ambas as comunidades de fala, a distribuição dos conectores sequenciadores no que tange ao nível de escolaridade revela uma oposição entre aí, conector marcado estilisticamente como informal (e, por vezes, até estigmatizado), que predomina na fala de indivíduos menos escolarizados, e $e$ e então, conectores de maior prestígio (ou, ao menos, estilisticamente neutros), que recebem maior destaque na fala de indivíduos mais escolarizados.

Não é apenas sobre o que é comum às comunidades de fala que recai o interesse de um estudo sociolinguístico comparativo: a comparação pode auxiliar na descoberta de especificidades de comunidades particulares. Todavia, como vimos, os resultados foram bastante similares ao cotejarmos as comunidades de fala de Natal e de Florianópolis no que se refere à distribuição dos conectores sequenciadores nos dois níveis de escolaridade controlados.

Os gráficos a seguir deixam bastante salientes as grandes semelhanças existentes entre os pesos relativos atribuídos a cada conector por nível de escolaridade em Natal e em Florianópolis. O primeiro gráfico corresponde a $e$, o segundo a aí e o terceiro a então. 


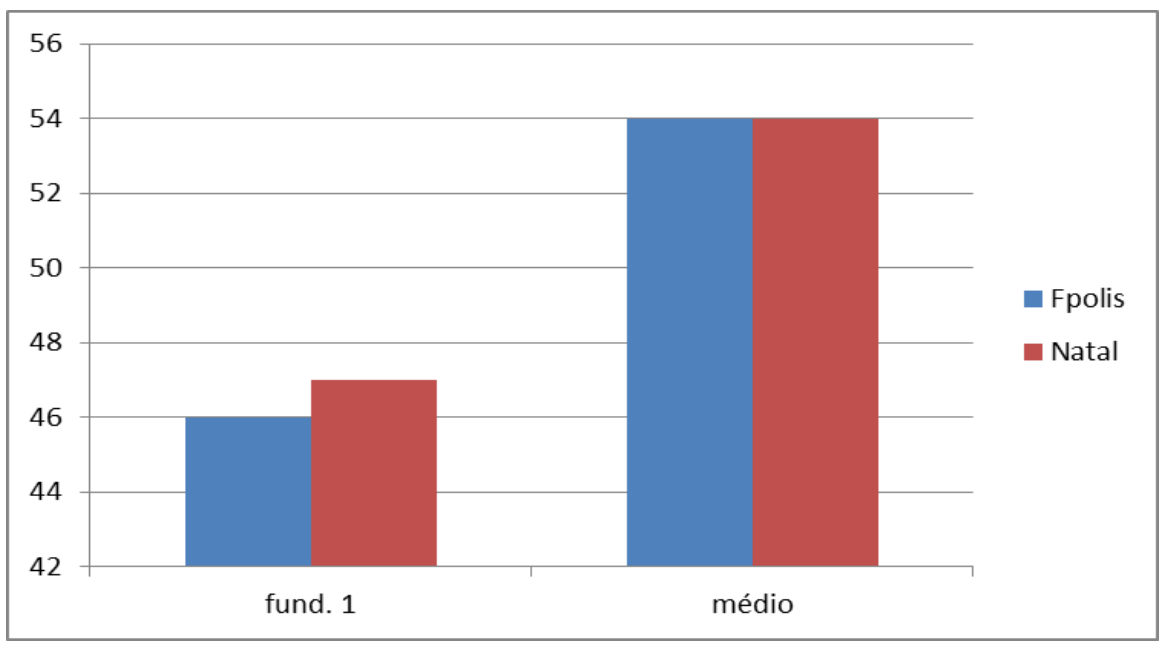

Gráfico 1: P.R. do conector $\boldsymbol{e}$ por nível de escolaridade Fonte: Elaboração própria.

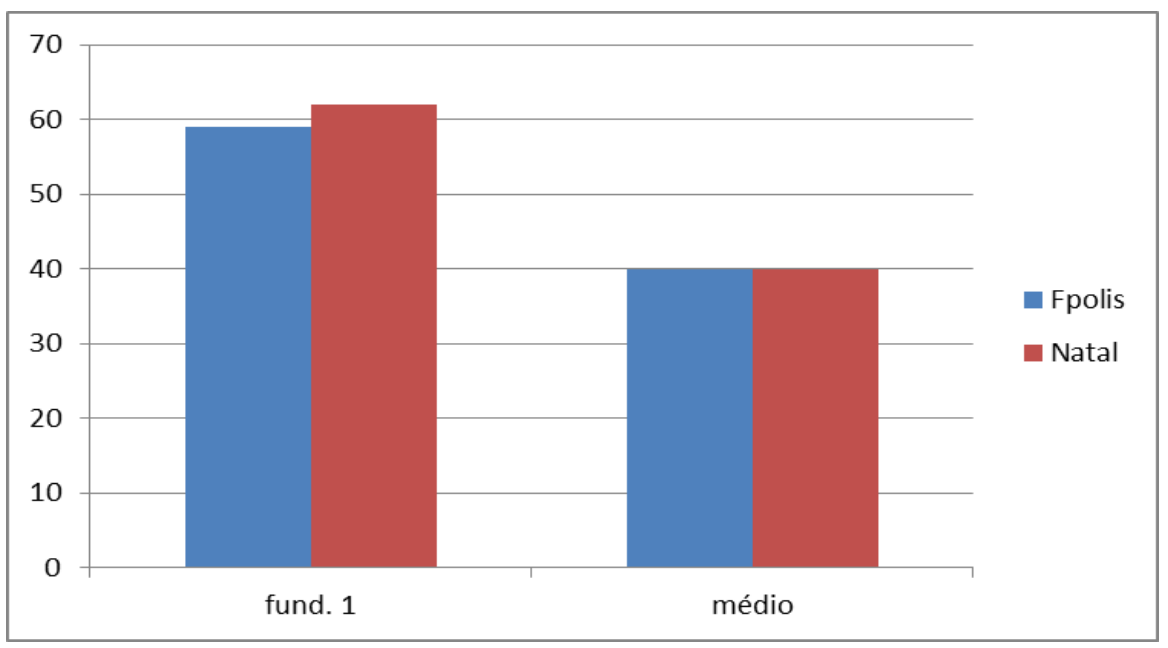

Gráfico 2: P.R. do conector aí por nível de escolaridade Fonte: Elaboração própria.

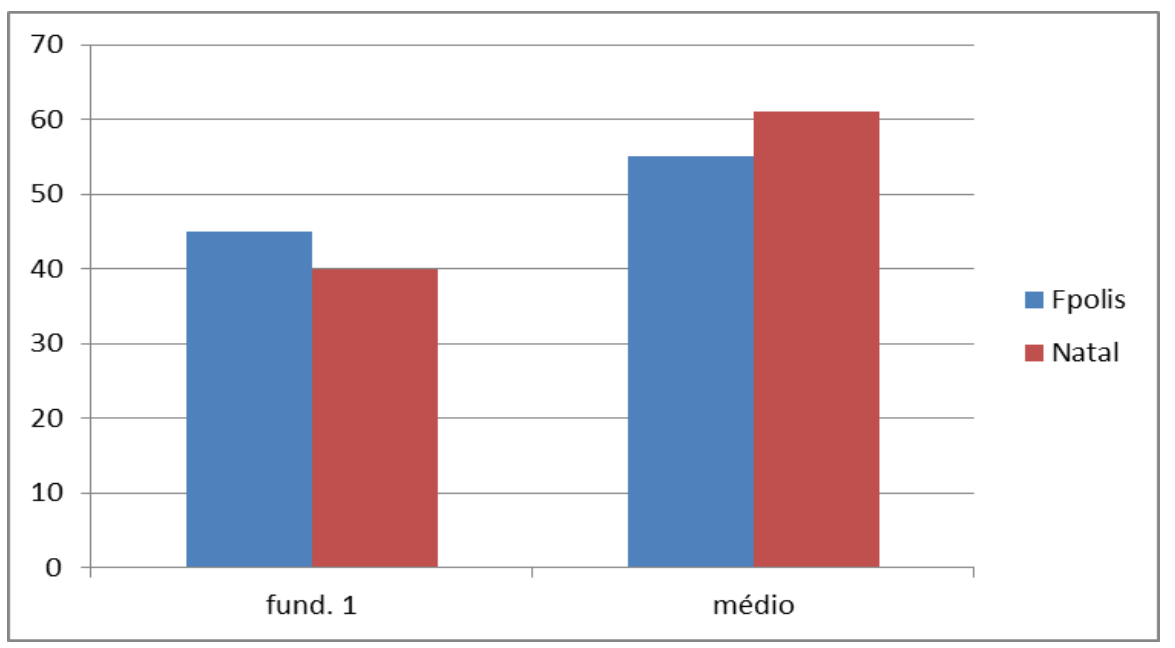

Gráfico 3: P.R. do conector então por nível de escolaridade Fonte: Elaboração própria. 
Cumpridos dois dos objetivos deste estudo sociolinguístico comparativo - analisar possíveis influências advindas do nível de escolaridade sobre o uso dos conectores sequenciadores $e$, aí e então em duas comunidades de fala brasileiras, Natal e Florianópolis, e cotejar os resultados obtidos para ambas as comunidades de fala a fim de identificar semelhanças e diferenças nos padrões de distribuição por nível de escolaridade de cada conector sequenciador -, resta dar conta do terceiro objetivo, qual seja, verificar se a generalização sociolinguística tangente à relação entre escolarização continuada e o emprego de formas variantes é válida para o caso dos conectores em tela.

Retomemos essa generalização: níveis mais altos de escolaridade se correlacionam com traços linguísticos avaliados positivamente pela comunidade de fala - os traços linguísticos ditos "prestigiados"; em contraparte, níveis mais baixos de escolaridade se correlacionam com traços linguísticos avaliados negativamente pela comunidade de fala - os traços linguísticos tidos como informais ou mesmo estigmatizados.

Os resultados obtidos neste estudo permitem validar essa generalização para o caso dos conectores sequenciadores, não apenas em uma, mas em duas comunidades de fala brasileiras: por um lado, o nível de escolaridade mais alto aqui controlado, Ensino Médio completo, correlaciona-se ao uso de $e$ e então, conectores avaliados positivamente por ambas as comunidades de fala (cf. testes de atitude linguística feitos por Silva (2013) e Tavares (2014)); por outro lado, o nível de escolaridade mais baixo aqui controlado, Ensino Fundamental 1, correlaciona-se ao uso de aí, conector negativamente avaliado por ambas as comunidades de fala, em que foi considerado típico de situações de interação informais ou mesmo estigmatizado.

Esses resultados representam, por conseguinte, novas evidências para a sustentação da generalização sociolinguística ligada à escolarização acima referida. Além disso, os resultados mostram que tal generalização pode ser estendida a fenômenos variáveis de nível discursivo, caso da sequenciação retroativo-propulsora de informações.

Também é digno de nota que pode haver um comportamento bastante uniforme nos dialetos do português brasileiro em geral no que diz respeito à influência da escolarização continuada sobre o uso dos conectores sequenciadores $e$, aí e então, já que duas comunidades de fala de diferentes regiões do país - Sul e Nordeste - apresentam comportamento muito semelhante.

Nessa ótica, é importante mencionar a pesquisa efetuada por Silva e Macedo (1989) abordando a variação entre os conectores $e$ e aí com base em dados do Rio de Janeiro (RJ), no Sudeste do Brasil. As autoras chegaram a resultados semelhantes aos obtidos por este estudo no que se refere ao padrão de distribuição de aí quanto ao nível de escolaridade: “(...) quanto menor for o nível de escolaridade, maior é o uso do conectivo ẩ' (Silva e Macedo 1989: 72), o que é mais um indício de que pode haver um mesmo padrão de distribuição no português brasileiro como um todo quanto à influência da escolarização continuada sobre o uso de aí.

Face aos resultados obtidos neste estudo, urge ressaltar que não compete à escola barrar a variação linguística (embora ela às vezes se empenhe nessa tarefa, como parece ser o caso no que se refere ao conector aí), mas sim apresentar aos alunos as formas linguísticas em seus contextos de uso e todas as implicações desse uso, o que envolve desde quem usa, quando usa, por que usa, em que gêneros textuais, modalidades, estilos, com que efeitos semântico-pragmáticos, com que intenções, e qual avaliação a comunidade tende a ter a respeito desses usos na atualidade, avaliação essa que pode ser discutida criticamente. 
Apesar de ter seu uso recriminado nas escolas, aí é utilizado como conector sequenciador não apenas na fala informal, mas também na escrita, em diferentes gêneros, especialmente naqueles marcados por maior informalidade, como contos e romances adultos e infanto-juvenis, crônicas, peças teatrais, histórias em quadrinhos, tirinhas, transcrição de entrevistas em jornais e revistas, letras de música, e-mails, blogs, mensagens no twitter etc. (cf. Tavares 2013).

Portanto, no que concerne a variantes que tipicamente emergem em contextos informais de uso, a exemplo do conector aí, a escola poderia abrir espaço para seu estudo, não como forma de estimular o seu abandono, e sim como forma de compreensão e apreciação não apenas da fala cotidiana, mas também da literatura, da música, do jornalismo, entre outros domínios em que variantes dessa natureza podem aflorar.

\section{Considerações finais}

Neste texto, foi apresentada uma análise sociolinguística comparativa envolvendo a função gramatical de sequenciação retroativo-propulsora de informações, tendo como variantes os conectores que mais frequentemente codificam essa função no português brasileiro oral, $e$, aí e então. As comunidades de fala selecionadas para o cotejamento localizam-se em duas regiões brasileiras distintas (e relativamente distantes), nos municípios de Natal (RN) e de Florianópolis (SC). O alvo da investigação foi a questão da influência do nível de escolaridade dos informantes sobre o uso variável dos conectores em enfoque.

Como os procedimentos de análise adotados para os dados oriundos de cada uma das comunidades de fala foram muito similares, os resultados referentes a Natal foram facilmente comparáveis aos resultados referentes a Florianópolis, garantindo-se, assim, a uniformidade teóricometodológica tão cara a estudos na linha da sociolinguística comparativa.

Os resultados obtidos atestaram, em ambas as comunidades de fala, as hipóteses iniciais, isto é, de que aí, conector sequenciador marcadamente informal, seria favorecido na fala de indivíduos com menos tempo de escolarização, ao passo que $e$ e então, conectores mais prestigiados, seriam favorecidos na fala de indivíduos com mais tempo de escolarização. Além disso, os resultados revelaram a grande semelhança existente, em Natal e em Florianópolis, entre os padrões de distribuição dos conectores $e$, aí e então em termos dos dois níveis de escolaridade controlados, Ensino Fundamental 1 e Ensino Médio.

Essa semelhança, que se reflete em pesos relativos bastante próximos, indicia a possibilidade de haver fortes tendências nacionais de distribuição dos conectores sequenciadores entre indivíduos mais e menos escolarizados, tendências essas que, como vimos, enquadram-se em uma generalização relativa ao nível de escolaridade construída no âmbito da sociolinguística variacionista. Entretanto, para obter mais evidências confirmadoras dessa possibilidade, necessária se faz a realização de novas pesquisas que tomem como variantes os conectores sequenciadores em outras comunidades de fala brasileira ainda não investigadas.

\section{Referências Bibliográficas}

Abreu, Maria Teresa Tedesco Vilardo. 1992. Elementos conjuntivos: sua variação em narrativas orais e escritas, Dissertação de Mestrado, Universidade Federal do Rio de Janeiro, Rio de Janeiro. Inédita. 
Buchstaller, Isabelle e Alexandra D’Arcy. 2009. Localized globalization: a multi-local, multivariate investigation of quotative be like, Journal of Sociolinguistics, 13: 291-331.

Coelho, Izete Lehmkuhl, Edair Maria Görski, Christiane Maria Nunes de Souza e Guilherme Henrique May. 2015. Para conhecer sociolinguística, São Paulo, Contexto.

Freitag, Raquel Meister Ko. et al. 2013. Gramática, interação e ensino de língua materna: procedimentos discursivos na fala de Itabaiana/SE, Interfaces Científicas (Educação), 1: 7184.

Givón, Talmy. 1984. Syntax: a functional-typological introduction, Amsterdam, John Benjamins.

Givón, Talmy. 1995. Functionalism and grammar, Amsterdam, John Benjamins.

Givón, Talmy. 2002. Bio-Linguistics: the Santa Barbara lectures, Amsterdam, John Benjamins.

Guy, Gregory Riordan e Ana Maria Stahl Zilles. 2007. Sociolinguística quantitativa: instrumental de análise, São Paulo, Parábola.

Labov, William. 1972. Sociolinguistic patterns, Philadelphia, University of Pennsylvania Press.

Labov, William. 1984. Field methods of the project on linguistic change and variation, em J. Baugh e J. Sherzer (eds.), Language in use, Englewood Cliffs, Prentice Hall: 28-53.

Labov, William. 1994. Principles of linguistic change: internal factors, Oxford, Blackwell.

Labov, William. 2001. Principles of linguistic change: social factors, Oxford, Blackwell.

Labov, William. [1969] 2003. Some sociolinguistic principles, em C. B. Paulston e G. R. Tucker (eds.), Sociolinguistics: the essential readings, Oxford, Blackwell: 234-250.

Labov, William. 2010. Principles of linguistic change: cognitive and cultural factors, Oxford, Blackwell.

Lenker, Ursula. 2011. A focus on adverbial connectors: connecting, partitioning and focusing attention in the history of English, Studies in Variation, Contacts and Change in English, 8: 123.

Macaulay, Ronald. 1991. Locating dialect in discourse: the language of honest men and bonnie lasses in Ayr, Oxford, Oxford University Press.

Macaulay, Ronald. 2002. Discourse variation, em J. K. Chambers, P. Trudgill e N. Shilling-Estes (eds.), The handbook of language variation and change, Cambridge, Blackwell: 283-305.

Macaulay, Ronald. 2005. Talk that counts: age, gender, and social class differences in discourse, Oxford, Oxford University Press.

Milroy, Lesley and Matthew Gordon. 2003. Sociolinguistics: method and interpretation, Oxford, Blackwell.

Pichler, Heike. 2010. Methods in discourse variation analysis: reflections on the way forward, Journal of Sociolinguistics, 14: 581-608.

Pichler, Heike. 2013. The structure of discourse-pragmatic variation, Amsterdam, John Benjamins.

Ramos, Jânia Martins e Maria Eugênia Lammoglia Duarte. 2003. O papel da sociolinguística no ensino da escrita padrão, Revista do GELNE, 5: 91-96.

Risso, Mercedes Sanfelice. 1996. O articulador discursivo "então”, em A. T. Castilho e M. Basílio (eds.), Gramática do português falado, v. 4, Campinas, Editora da UNICAMP/FAPESP: 423451.

Sankoff, David, Sali A. Tagliamonte e Eric Smith. 2005. Goldvarb X: a multivariate analysis application, Toronto, e Ottawa [en linea] Disponivel em http://individual.utoronto.ca/tagliamonte/Goldvarb/GV_index.htm\#ref.

Santos, Leonor Werneck. 2003. Articulação textual na literatura infantil e juvenil, Rio de Janeiro, Lucerna.

Schilling-Estes, Natalie. 2007. Sociolinguistic fieldwork, em R. Bayley e C. Lucas (eds.), Sociolinguistic variation: theories, methods and applications, Cambridge, Cambridge University Press: 165-189.

Silva, Giselle Machline de Oliveira e Alzira Verthein Tavares de Macedo. 1989. Análise sociolinguística de alguns marcadores conversacionais: V Relatório de Pesquisa: Projetos Mecanismos Funcionais de Uso Linguístico, Rio de Janeiro, UFRJ. Inédito. 
Silva, Washintiane Patrícia Barbosa. 2013. Conectores sequenciadores E e AÍ em contos e narrativas de experiência pessoal escritos por alunos de ensino fundamental: uma abordagem sociofuncionalista, Dissertação de Mestrado, Universidade Federal do Rio Grande do Norte, Natal. Inédita.

Tagliamonte, Sali A. 2002. Comparative sociolinguistics, em J. K. Chambers, P. Trudgill e N. Shilling-Estes (eds.), The handbook of language variation and change, Cambridge, Blackwell: 729-763.

Tagliamonte, Sali A. 2006. Analysing sociolinguistic variation, Cambridge, Cambridge University Press.

Tagliamonte, Sali A. 2012. Variationist sociolinguistics: change, observation, interpretation, Cambridge, Wiley-Blackwell.

Tagliamonte, Sali A. 2015. Exploring the architecture of variable systems to predict language change, Studies in Variation, Contacts and Change in English, 16: 1-13.

Tagliamonte, Sali A. e Alexandra D'Arcy. 2007. The modals of obligation/necessity in Canadian perspective, English World-Wide, 28: 47-87.

Tagliamonte, Sali A. e Alexandra D'Arcy. 2009. Peaks beyond phonology: adolescence, incrementation, and language change, Language, 85: 58-107.

Tagliamonte, Sali A., Mercedes Durham e Jennifer Smith. 2014. Grammaticalization at an early stage: future be going to in conservative British dialects, English Language and Linguistics, 18: 75-108.

Tavares, Maria Alice. 2012. Gramática emergente: recorte de uma construção gramatical, em E. R. Souza (ed.), Funcionalismo linguístico: análise e descrição, São Paulo, Contexto: 33-51.

Tavares, Maria Alice. 2013. Gramática na sala de aula: o olhar da sociolinguística variacionista, em M. A. Martins e M. A. Tavares (eds.), Contribuições da sociolinguística e da linguística histórica para o ensino de língua portuguesa, Natal, EDUFRN: 91-112.

Tavares, Maria Alice. 2014. A gramaticalização de E, AÍ, DAÍ e ENTÃO: variação e mudança em uma perspectiva sociofuncionalista. Natal, EDUFRN.

Torres Cacoullos, Rena. 2001. From lexical to grammatical to social meaning, Language in Society, 30: 443-478.

Torres Cacoullos, Rena e James A. Walker. 2009. The present of the English future: grammatical variation and collocations in discourse, Language, 85: 321-354.

Travaglia, Luiz Carlos, Maura Alves de Freitas Rocha e Vania Maria Bernardes Arruda Fernandes. 2009. A aventura da linguagem: língua portuguesa, $9^{\circ}$ ano, Belo Horizonte, Dimensão.

Votre, Sebastião Josué. 2003. Relevância da variável escolaridade, em M. C. Mollica e M. L. Braga (eds.), Introdução à sociolinguística: o tratamento da variação, São Paulo, Contexto: 51-58.

Watt, Dominic. 2007. Variation and the variable, em C. Llamas, L. Mullany and P. Stockwell (eds.), The Routledge companion to sociolinguistics, New York, Routledge: 3-11. 